\title{
Estimating Cerebral Blood Flow in Newborn Infants: Comparison of Near Infrared Spectroscopy and ${ }^{133} \mathrm{Xe}$ Clearance
}

\author{
L. SKOV, O. PRYDS, AND G. GREISEN \\ Department of Neonatology, University Hospital (Rigshospitalet), Copenhagen, Denmark
}

\begin{abstract}
A new method of measuring cerebral blood flow (CBF) in newborn infants by means of near infrared spectroscopy (CBFnirs) was compared with the i.v. ${ }^{133} \mathrm{Xe}$ clearance technique (CBFxe). Forty CBFnirs measurements were obtained during $19{ }^{133} \mathrm{Xe}$ measurements in 16 infants; 79 other CBFnirs data sets were discarded because the assumptions for their use were not fulfilled. The testretest variation of repeated near infrared-measurements during each ${ }^{133} \mathrm{Xe}$ clearance was $17.5 \%$. CBFnirs was closely related to CBFxe $\left(r^{2}=0.84, p<0.0001\right)$, with a slope of $0.75(\mathrm{SEM}=0.064)$ and a intercept of $1.58 \mathrm{~mL} /$ $100 \mathrm{~g} / \mathrm{min}(\mathrm{SEM}=0.51)$. The difference between the measurements obtained by the two methods (CBFnirs CBFxe) was negative in the high range of $C B F$, whereas the difference was close to zero in the low range. We conclude that CBF measured with near infrared spectroscopy was in good agreement with the CBF measured with the ${ }^{133} \mathrm{Xe}$ method. The near infrared spectroscopy method has the advantage of being noninvasive, and it does not involve ionizing radiation. Because of methodologic constraints, however, it may underestimate CBF in the high range of flow, and it may have limitations of application in clinical research. (Pediatr Res 30: 570-573, 1991)
\end{abstract}

\section{Abbreviations}

CBF, cerebral blood flow

CBFxe, cerebral blood flow measured with the ${ }^{133} \mathrm{Xe}$ technique

CBFnirs, cerebral blood flow measured with near infrared spectroscopy

NIRS, near infrared spectroscopy

$\mathrm{SaO}_{2}$, arterial blood oxygen saturation

Abnormalities of CBF may play a crucial role in the pathogenesis of cerebral ischemia and hemorrhage, the commonest causes of neurodevelopment disability in children needing intensive care neonatally. When studying cerebral circulation, it is important to consider the safety, practical applicability, and quantitative accuracy before selecting an experimental method. Estimation of $\mathrm{CBF}$ in newborn children with i.v. ${ }^{133} \mathrm{Xe}$ clearance has been used for several years (1-3). Recently, a new method of quantifying CBF using NIRS was described (4). The present study compares these two methods for measuring CBF in sick, newborn infants.

Correspondence and reprint requests: Liselotte Skov, M.D., Department of Neonatology, Rigshospitalet, Blegdamsvej 9, 2100 Copenhagen $\varnothing$, Denmark.

Received April 4, 1991; accepted July 5, 1991.

\section{PATIENTS AND METHODS}

Cerebral blood flow was measured simultaneously by ${ }^{133} \mathrm{Xe}$ clearance and by NIRS in 29 newborn infants. In 13 infants, all of the 38 attempts of NIRS measurements were rejected because of insufficient quality, whereas none of the Xe measurements were rejected. In the remaining 16 infants, with a total of $19 \mathrm{Xe}$ measurements, 41 out of 81 NIRS curves were rejected, leaving 40 measurements for analysis.

A total of $79 \mathrm{CBF}$ irs curves did not meet the quality criteria (see below): In five measurements $\mathrm{SaO}_{2}$ increased insufficiently; in 20 measurements baseline $\mathrm{SaO}_{2}$ was unstable; in 10 measurements changes in cerebral oxygenation index were delayed more than $8 \mathrm{~s}$ in proportion to changes in $\mathrm{SaO}_{2}$; in 12 measurements cerebral oxygenation index did not increase markedly; and in 27 measurements cerebral blood volume changed significantly. The curve quality was not related to the magnitude of CBFxe, the inspiratory fraction of oxygen, or patient characteristics. The mean gestational age of the 16 infants was 30.7 wk (range 26-39 wk), and the mean birth weight was $1753 \mathrm{~g}$ (range $860-2485 \mathrm{~g}$ ). The mean postnatal age at CBF investigation was $28 \mathrm{~h}$ (range 9$74 \mathrm{~h}$ ) and the inspiratory oxygen fraction averaged $45 \%$ (range $30-60 \%$ ). Eleven infants were mechanically ventilated because of respiratory distress and the remaining infants, because of severe birth asphyxia.

Method. NIRS depends on the relative transparency of the neonate's head to near infrared light, which is attenuated by scattering and absorption in the tissues (5). Our NIRS instrument (Radiometer, Copenhagen, Denmark) uses four semiconductor laser diodes with wavelengths of $775,805,845$, and $904 \mathrm{~nm}$. The lasers were operated sequentially and pulsed for $200 \mathrm{~ns}$ with a repetition rate of $500 \mathrm{~Hz}$. Optical fiber bundles are used to transmit and receive the light. For calculation of the cerebral oxyhemoglobin concentration, the optical path length must be known and the algorithm for determining changes in cerebral $\mathrm{Hb}$ density must be quantitatively correct (5). In this study, we have used the assumption that the optical path length is 4.39 times the interoptode distance (6).

CBFnirs theory. The method is based on the Fick principle, according to which the amount of a substance taken up by an organ per unit of time is equal to the arterial concentration of the substance minus the venous concentration times the blood flow.

$$
\mathrm{Q}(\mathrm{t})=\mathrm{F} \times \int_{0}^{\mathrm{t}}(\mathrm{Ca}-\mathrm{Cv}) \mathrm{dt}
$$

where $Q(t)$ is the amount of the tracer in tissue, $F$ is flow, and $\mathrm{Ca}$ and $\mathrm{Cv}$ are the concentrations of the tracer in arterial and venous blood, respectively. When the time, $t$, is less than the transit time through the organ, the tracer will not have reached the venous side. The flow $(F)$ can then be measured as the ratio between the amount of tracer accumulated in the brain and the amount of tracer introduced during the period $0-\mathrm{t}$. With NIRS it is possible to measure changes in oxygenated and deoxygenated 
$\mathrm{Hb}$ concentration $\left(\left[\mathrm{HbO}_{2}\right]\right.$ and $\left.[\mathrm{HB}]\right)$ as well as changes in total cerebral $\mathrm{Hb}$ concentration (7). $\mathrm{SaO}_{2}$ is measured by a pulse oximeter placed on the right hand of the infant.

After a sudden increase in the concentration of inspired oxygen, the increase in cerebral oxyhemoglobin represents the accumulation of tracer. The product of the integral of change in $\mathrm{SaO}_{2}$ with respect to time and the arterial $\mathrm{Hb}$ concentration $(\mathrm{aHb})$ is the arterial tracer concentration and, therefore,

$$
\mathrm{CBF}=\mathrm{OI} / \mathrm{aHb} \times \int_{0}^{\mathrm{t}}\left(\mathrm{SaO}_{2}\right) \mathrm{dt}
$$

where $\left.\mathrm{OI}\left[\mathrm{HbO}_{2}-\mathrm{HB}\right) / 2\right]$ is expressed in $\mathrm{mmol} / 100 \mathrm{~g}$ brain wt, $\mathrm{aHb}$ in $\mathrm{mmol} / \mathrm{mL}$ tetraheme, and $\int_{0}^{t}\left(\mathrm{SaO}_{2}\right) \mathrm{dt}$ in min.

Methodologic requirements. The delay time (the difference between the lung-to-brain and the lung-to-hand circulation times) must be known. This delay must be the same for different parts of the brain. The integration period, $t$, used (equation 2) must be less than the minimal cerebral transit time. Before measuring $\mathrm{CBF},\left[\mathrm{HbO}_{2}-\mathrm{HB}\right]$ and $\mathrm{SaO}_{2}$ should be stable for a period longer than the maximal cerebral transit time. During the measurement, $\mathrm{CBF}$, cerebral blood volume, and cerebral oxygen extraction must also be constant.

CBFxe. ${ }^{133} \mathrm{Xe}(0.5$ to $1.0 \mathrm{mCi} / \mathrm{kg})$ was injected in a peripheral vein, and the clearance was recorded by scintillators placed over one frontoparietal region and the thorax, respectively. A record- ing time of $15 \mathrm{~min}$ was used, and CBF was calculated from the time the activity of $\mathrm{Xe}$ in the lung had decreased to $15 \%$ of its peak activity (8).

Measurements. The NIRS measurements were performed during the ${ }^{133} \mathrm{Xe}$-clearance. NIRS signals were sampled every $0.5 \mathrm{~s}$. $\mathrm{SaO}_{2}$ was measured by a pulse oximeter (Datex, Helsinki, Finland) in the beat-to-beat mode placed on the right hand of the infant.

After a 1-min period with constant values of oxyhemoglobin and saturation, a transient increment of $5-10 \%$ in $\mathrm{SaO}_{2}$ was induced by briefly increasing the concentration of inspired oxygen to $100 \% . \mathrm{SaO}_{2}$ was maintained in the range of $80-98 \%$. The analysis of the NIRS curves including quality check of the raw data and rejection of the measurement or calculation of CBF from $7.5 \mathrm{~s}$ integration time (CBFnirs 7.5 ) were made off-line by a custom-made computer program (Appendix). During the measurement of $\mathrm{CBF}$, arterial blood was sampled for analysis of arterial $\mathrm{O}_{2}$ and $\mathrm{CO}_{2}$ tensions. Mean arterial blood pressure was recorded from an indwelling umbilical catheter if in situ; otherwise, it was estimated by oscillometry (Dinamap; Critikon, Tampa, FL).

Statistics. I he CBF values were positively skewed and were transformed logarithmically to obtain homogeneity of variance. Linear regression and one-way analysis of variance were used to compare the data and for estimation of test-retest variability.

Table 1. Summarized data of 16 infants*

\begin{tabular}{|c|c|c|c|c|c|c|c|c|}
\hline $\begin{array}{c}\text { Infant } \\
\text { no. }\end{array}$ & $\begin{array}{c}\text { GA } \\
(w k)\end{array}$ & $\begin{array}{c}\text { Birth wt } \\
(\mathrm{g})\end{array}$ & $\begin{array}{l}\text { Age } \\
(\mathrm{h})\end{array}$ & $\begin{array}{l}\mathrm{PCO}_{2} \\
(\mathrm{kPa}) \\
\end{array}$ & $\begin{array}{c}\text { CBFxe } \\
(\mathrm{mL} / 100 \mathrm{~g} / \mathrm{min})\end{array}$ & $\begin{array}{c}\text { CBFNIRS7.5 } \\
(\mathrm{mL} / 100 \mathrm{~g} / \mathrm{min}) \\
\end{array}$ & $\begin{array}{l}\text { Mean CBFNIRS } \\
(\mathrm{mL} / 100 \mathrm{~g} / \mathrm{min})\end{array}$ & $\begin{array}{c}\text { CBFNIRS6 } \\
(\mathrm{mL} / 100 \mathrm{~g} / \mathrm{min})\end{array}$ \\
\hline 1 & 28 & 1405 & 40 & 4.9 & 7.80 & 5.86 & 5.86 & 9.47 \\
\hline 2 & 39 & 3485 & 10 & 3.4 & 20.00 & 17.39 & 17.40 & 21.40 \\
\hline 3 & 30 & 1807 & 12 & 3.8 & 7.20 & 5.04 & 6.21 & 4.74 \\
\hline 3 & & & & 3.8 & & 6.00 & & 7.60 \\
\hline 3 & & & & 3.8 & & 7.52 & & 9.52 \\
\hline 4 & 27 & 1075 & 74 & 5.5 & 8.00 & 6.62 & 7.24 & 8.52 \\
\hline 4 & & & & 5.5 & & 8.83 & & 10.03 \\
\hline 4 & & & & 5.5 & & 6.28 & & 6.98 \\
\hline 5 & 27 & 880 & 11 & 4.4 & 8.50 & 7.59 & 7.38 & 9.59 \\
\hline 5 & & & & 4.4 & & 7.11 & & 8.31 \\
\hline 6 & 38 & 2750 & 12 & 4.3 & 5.10 & 7.11 & 7.04 & 2.71 \\
\hline 6 & & & & 4.3 & & 6.97 & & 13.07 \\
\hline 7 & 30 & 1100 & 46 & 4.3 & 8.60 & 7.04 & 8.63 & 5.84 \\
\hline 7 & & & & 4.3 & & 7.87 & & 8.37 \\
\hline 7 & & & & 4.3 & & 10.90 & & 11.40 \\
\hline 8 & 29 & 1200 & 24 & 5.3 & 15.60 & 7.59 & 7.59 & 10.69 \\
\hline 9 & 27 & 960 & 9 & 3.6 & 19.20 & 19.32 & 16.30 & 20.72 \\
\hline 9 & & & & 3.6 & & 13.18 & & 15.68 \\
\hline 9 & & & & 5.1 & 28.00 & 17.60 & 21.00 & 26.40 \\
\hline 9 & & & & 5.1 & & 24.56 & & 35.26 \\
\hline 10 & 29 & 1255 & 13 & 4.5 & 11.00 & 8.28 & 8.28 & 7.98 \\
\hline 10 & & & & 3.2 & 8.60 & 7.38 & 7.38 & 7.98 \\
\hline 11 & 26 & 910 & 36 & 5.1 & 9.80 & 10.00 & 8.76 & 10.20 \\
\hline 11 & & & & 5.1 & & 8.97 & & 9.47 \\
\hline 11 & & & & 5.1 & & 8.83 & & 9.03 \\
\hline 11 & & & & 5.1 & & 7.80 & & 9.00 \\
\hline 11 & & & & 5.1 & & 8.14 & & 7.94 \\
\hline 12 & 38 & 3300 & 34 & 4.7 & 21.90 & 14.56 & 12.60 & 15.36 \\
\hline 12 & & & & 4.7 & & 10.56 & & 10.26 \\
\hline 12 & & & & 4.7 & & 12.35 & & 13.45 \\
\hline 12 & & & & 4.7 & & 12.97 & & 14.57 \\
\hline 12 & & & & 4.8 & 20.10 & 14.15 & 16.60 & 19.55 \\
\hline 12 & & & & 4.8 & & 19.11 & & 23.61 \\
\hline 13 & 26 & 860 & 36 & 4.8 & 26.00 & 15.73 & 15.70 & 16.73 \\
\hline 14 & 37 & 2470 & 18 & 4.7 & 18.20 & 18.91 & 17.50 & 29.41 \\
\hline 14 & & & & 4.7 & & 16.01 & & 14.41 \\
\hline 15 & 33 & 3420 & 50 & 2.6 & 19.00 & 12.01 & 11.50 & 21.61 \\
\hline 15 & & & & 2.6 & & 10.90 & & 13.60 \\
\hline 16 & 28 & 1168 & 36 & 5.1 & 30.40 & 26.08 & 26.00 & 31.48 \\
\hline 16 & & & & 5.1 & & 25.94 & & 34.14 \\
\hline
\end{tabular}

${ }^{*} \mathrm{GA}$, gestation age:postnatal age; CBFNIRS6, CBF calculated from $6 \mathrm{~s}$ integration; CBFNIRS7.5, CBF calculated from $7.5 \mathrm{~s}$ integration. 
The study was approved by the Ethics Committee for Greater Copenhagen, and parental informed consent was obtained for each infant investigated.

\section{RESULTS}

The 40 measurements of CBFnirs in the 16 infants averaged $11.7 \mathrm{~mL} / 100 \mathrm{~g} / \mathrm{min}(5.0-26.1 \mathrm{~mL} / 100 \mathrm{~g} / \mathrm{min})$, whereas CBFxe averaged $14.8 \mathrm{~mL} / 100 \mathrm{~g} / \mathrm{min}(5.1-30.4 \mathrm{~mL} / 100 \mathrm{~g} / \mathrm{min}$ ) (Table 1).

The test-retest variation of the repeated NIRS measurements during each ${ }^{133} \mathrm{Xe}$ clearance was $17.5 \%$. To improve the estimation of CBFnirs, the mean value of CBFnirs for each CBFxe was calculated. Because different numbers of investigations of CBFnirs were performed, the regression analysis was weighted by the numbers. Linear regression analysis between the mean CBFnirs and CBFxe yielded a slope of $0.75(\mathrm{SE}=0.064)$ with an intercept of $1.58 \mathrm{~mL} / 100 \mathrm{~g} / \mathrm{min}(\mathrm{SE}=0.51)\left(r^{2}=0.84, p<\right.$ 0.0001 ) (Fig. 1).

Several sets of measurements obtained in the same infants cannot, strictly speaking, be regarded as independent observations. We therefore compared the logarithmically transformed value of the first CBFnirs and the first CBFxe in each infant. In these 16 paired data sets, the mean of the difference was -23.3 $\pm 6.8 \%(p<0.005)$, and the underestimation of CBFnirs was equal in the high and the low levels of CBF.

Because we do not know the true value of $\mathrm{CBF}$, the mean of the results of the two measurements $[1 / 2 \times($ CBFnirs + CBFxe $)]$ was therefore used as the best estimate (9). The difference of the values between the two methods (CBFnirs - CBFxe) revealed lower values of the CBFnirs compared with the CBFxe in the high range of $\mathrm{CBF}$, whereas the difference was close to zero in the low range (Fig. 2).

To examine the effect of a shorter integration period, we also calculated $\mathrm{CBF}$ from a 6-s integration time $\left(\mathrm{CBFnirs}_{6.0}\right)$. Higher CBFnirs values were obtained with a 6.0 -s integration time, and they were closer to the values of CBFxe (Fig. 3). The difference between $\mathrm{CBF}$ irs $_{6.0}$ and $\mathrm{CBFnirs}_{7.5}$ was greater at high values of CBF $(p<0.0003)$. The test-retest variation of CBFnirs 6.0 , however, was as high as $40 \%$ (analysis of variance).

\section{DISCUSSION}

NIRS allows a noninvasive estimate of cerebral hemodynamics at the cotside. The method does not expose the infant to ionizing radiation, and it can be repeated as often as necessary without disturbing the infant. To quantify the NIRS signals in terms of $\mathrm{mL} / 100 \mathrm{~g} / \mathrm{min}$, an algorithm obtained from in vitro experiments

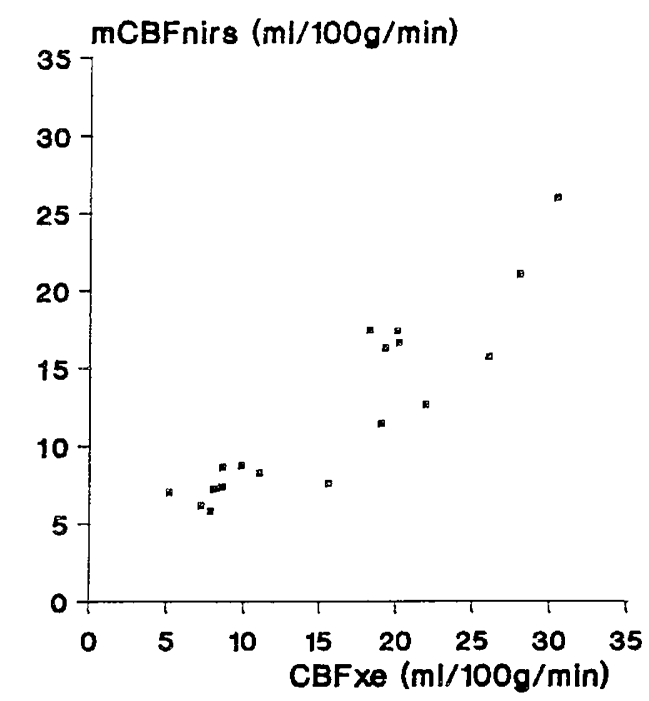

Fig. 1. CBFxe plotted against mean of CBFnirs.

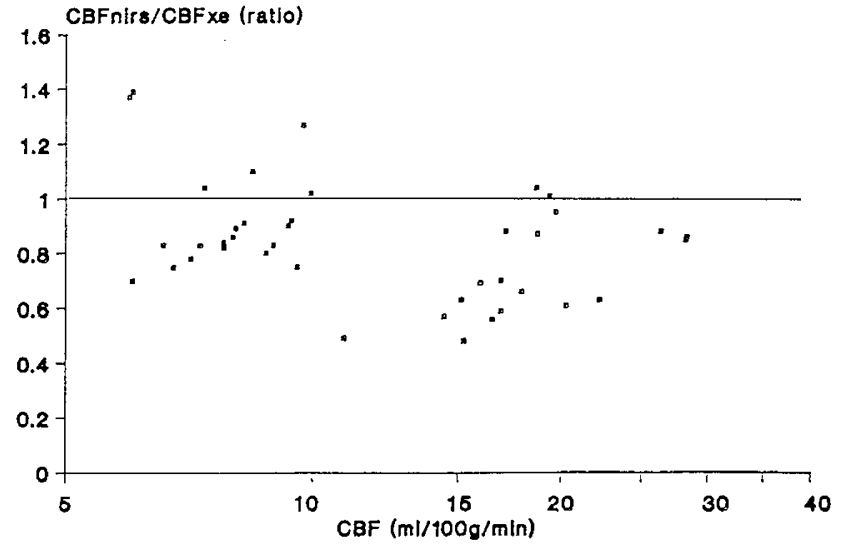

Fig. 2. $\mathrm{CBF}$ calculated as the geometrical mean of CBFnir and $\mathrm{CBFxe}$ against their difference, expressed as the ratio CBFnir/CBFxe. Consistently negative differences are seen in the high range of CBF. (The geometrical mean and the ratio were used to obtain constant variance over the range of $\mathrm{CBF}$, for the purpose of significance testing.)

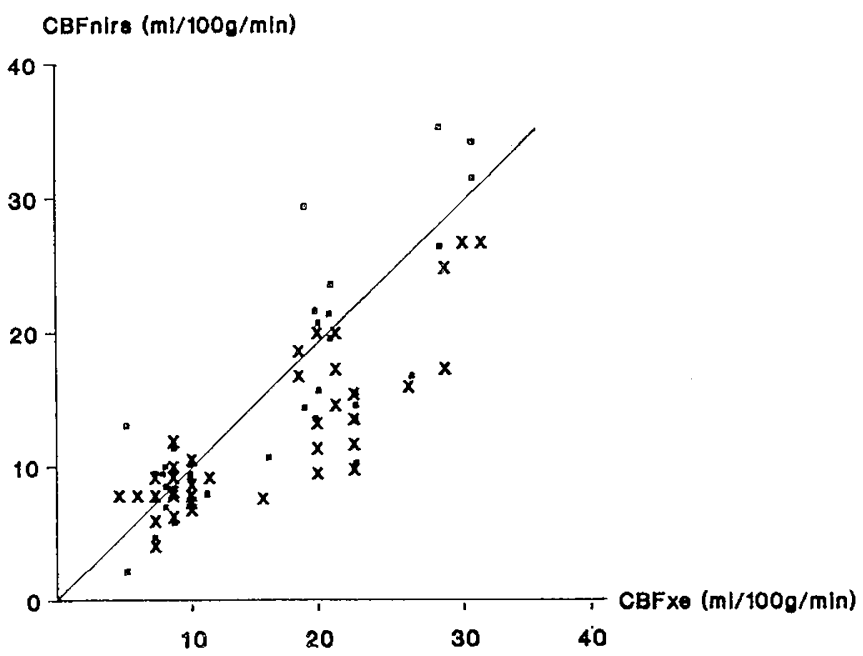

Fig. 3. $\mathrm{CBF} \mathrm{CBr}_{7.5}(\times)$ and $\mathrm{CBFnirs}_{6.0}(\mathbf{a})$ against CBFxe. Line of identity is shown. The higher values of $\mathrm{CBFnirs}_{6.0}$ are seen, in particular in the high range of CBF. The greater variability of the CBFnirs 6.0 is also seen.

$(5,10)$ and a path length factor obtained by measurements of time of flight of photons in infants' brains post-mortem (7) was used. Despite the potential errors introduced hereby, the agreement between CBF values obtained by NIRS and ${ }^{133} \mathrm{Xe}$ was acceptable. Furthermore, the correlation between the two methods was quite good in the wide range of values of CBF obtained in different clinical situations of preterm infants with respiratory distress and in asphyxiated full-term infants.

In the present study, we have compared two indirect methods of measuring CBF, an established technique and a new technique. Although ${ }^{133} \mathrm{Xe}$ clearance has been firmly established for measurement of $\mathrm{CBF}$ in adults (11) and has proved to be a useful method for measuring $\mathrm{CBF}$ in the newborn, it has some problems. The test-retest variation for CBFxe is not less than 10-15\% $(2,12)$. Furthermore, Xe can diffuse from vein to artery during washout. This will result in undetected recirculation and a slower clearance and, therefore, in an underestimation of the flow rate, which will be greater at low levels of flow (13). We found, however, the best agreement between the two methods in the low range of $\mathrm{CBF}$.

The greatest problems in measuring $\mathrm{CBF}$ with an intraarterial tracer is that the transit time is very short (seconds) and the time resolution of NIRS as well as pulse oximetry has to be very good. In this study we have used an integration time of $7.5 \mathrm{~s}$. This 
integration time is similar to the transit time of $8 \mathrm{~s}$ reported by Arnot et al. (14) in 1970, using red blood cells labeled with carbon-11 monoxide. When using a shorter integration time for analysis (6 s instead of $7.5 \mathrm{~s}$ ), we obtained higher values of CBFnirs, resulting in values closer to the CBF-Xe. This was predictable: assuming cerebral blood volume to be $3 \mathrm{~mL} / 100 \mathrm{~g}$ (15), CBF of $30 \mathrm{~mL} / 100 \mathrm{~g} / \mathrm{min}$ corresponds to a mean transit time of $6 \mathrm{~s}$ only. Unfortunately, at the shorter integration period of $6 \mathrm{~s}$, the test-retest variation was as high as $40 \%$.

Estimates of CBF using ${ }^{133} \mathrm{Xe}$ clearance are based on a $15-\mathrm{min}$ recording period (the period $1-5$ min after ${ }^{133} \mathrm{Xe}$ injection carrying the most weight in computation of CBF). During this period, however, there can be some cyclical variation of $\mathrm{CBF}$ as recently reported on $\mathrm{CBF}$ velocity using on-line Doppler technique $(16,17)$. Such cyclical variation may contribute to the relatively high test-retest variation in CBFnirs, each measurement lasting only a few seconds. A test-retest variation of $17 \%$ at $7.5 \mathrm{~s}$ of integration may, however, call for an average of two to three measurements regardless of the cause.

Another consideration is which parts of the brain are represented by the two methods. By placing the optodes and scintillators close together, we attempted to make the fields of view similar: a 100 - to $200-\mathrm{mL}$ volume of both hemispheres.

Two thirds of the NIRS measurements were unsuccessful because the recordings were not of the required quality. Twentyseven of the measurements were rejected because of significant changes in cerebral blood volume. It is still unclear whether hyperoxia changes central or cerebral hemodynamics within a few seconds. Studies in animals and adult human subjects have shown that $\mathrm{CBF}$ and oxygen extraction are stable with change of arterial oxygen tension between 6 and $13 \mathrm{kPa}(18,19)$. Even a change in cerebral blood volume of only a few percent, however, will result in a proportional but relatively larger error in CBFnirs and thereby affect the CBFnirs estimation (20).

Another important problem appears for the use of NIRS as a CBF method in clinical research. It may be impossible to induce a sufficient rise (or fall) in $\mathrm{SaO}_{2}$ in infants with normal lung function and in infants with congenital heart disease, persistent fetal circulation, or severe respiratory distress syndrome.

We conclude that measurements of CBF with NIRS were in good agreement with results obtained by the ${ }^{133} \mathrm{Xe}$ method. The NIRS method has some advantages, although CBF may be underestimated in the high range of CBF because of methodologic constraints. The variation of $17 \%$ could demand an average of two to three measurements, thereby losing some of the advantage of the quick measurements. In addition, the method is likely to find limited application in clinical research.

\section{REFERENCES}

1. Greisen G 1986 Cerebral blood flow in preterm infants during the first week of life. Acta Paediatr Scand 75:43-51

2. Greisen G 1990 Cerebral blood flow in mechanically ventilated preterm neonates. Dan Med Bull 2:124-132

3. Jaggi JL, Lipp AE, Duc G 1989 Measurement of cerebral blood flow with a noninvasive ${ }^{133}$ Xenon method in preterm infants. In: Stern L, Friis-Hansen B (eds) Physiological Foundations of Perinatal Care. Elsevier, Amsterdam, pp 231-242

4. Edwards AD, Wyatt JS, Richardson C, Delpy DT, Cope M, Reynolds EOR 1988 Cotside measurements of cerebral blood flow in ill newborn infants by near infrared spectroscopy. Lancet 2:770-771

5. Jöbsis FF 1977 Noninvasive infrared monitoring of cerebral and myocardial oxygen sufficiency and circulatory parameters. Science 198:1264-1267

6. Wyatt JS, Cope M, Delpy DT, van der Zee P, Arridge S, Edwards AD, Wray SC, Reynold EOR 1989 Measurement of optical pathlength for cerebral near-infrared spectroscopy in newborn infants. Dev Neurosci 12:140-144

7. Pryds O, Greisen G, Skov L, Friis-Hansen B 1990 Carbon dioxide-related changes in cerebral blood volume and cerebral blood flow in mechanically ventilated, preterm neonates. Comparison of near infrared spectrophotometry and ${ }^{133}$ Xenon clearance. Pediatr Res 27:445-449

8. Greisen G, Frederiksen J, Mali J, Friis-Hansen B 1984 Analysis of cranial ${ }^{133}$ Xenon clearance in the newborn infants by the two-compartment model. Scand J Clin Lab Invest 44:239-250
9. Bland JM, Altman DG 1986 Statistical methods for assessing agreement between two methods of clinical measurement. Lancet 2:307-310

10. Wray S, Cope M, Delpy DT, Wyatt JS, Reynolds EOR 1988 Characterization of the near infrared absorption spectra of cytochrome $\mathrm{aa}_{3}$ and haemoglobin for the non-invasive monitoring of cerebral oxygenation. Biochim Biophys Acta 933:184-192

11. Obrist WD, Wilkinson WE 1990 Regional cerebral blood measurements in humans by ${ }^{133}$ Xenon clearance. Cerebrovasc Brain Metab Rev 2:283-327

12. Pryds O, Schneider S 1991 Aminophyllin induces cerebral vasoconstriction in stable, preterm infants without affecting the visual evoked potential. Eur $\mathbf{J}$ Pediatr 150:366-369

13. Greisen G, Trojaborg W 1987 Cerebral blood flow $\mathrm{P}_{\mathrm{a}} \mathrm{CO}_{2}$ changes, and visual evoked potentials in mechanically ventilated, preterm infants. Acta Paediatr Scand 76:394-400

14. Arnot RN, Glass HI, Clark JC, Davis JA, Schiff D, Picton-Warlow CG 1970 Methods of measurement of cerebral blood flow in the newborn infants using cyclotron produced isotopes. Radioactive Isotope Klinik Farschning 9:60-74

15. Wyatt J, Cope M, Delpy DT, Richardson CE, Edwards AD, Wray S, Reynolds EOR 1990 Quantification of cerebral blood volume in human infants by near-infrared spectroscopy. J Appl Physiol 68:1086-1091

16. Anthony MY, Edvans DH, Levine MI 1991 Cyclical variation in cerebral blood flow velocity. Arch Dis Child 66:12-16

17. Cowan F 1987 Cerebral blood velocity in the sleeping normal newborn infants Studies on the cerebral circulation of the newborn infants. Dissertation, University of Oslo, A/S Holstad-Trykk, Oslo, pp 107-131

18. Kogure K, Scheinberg P, Reinmuth OM, Fujishima M, Busto R 1970 Mechanism of cerebral vasodilatation in hypoxia. J Appl Physiol 29:223-229

19. Lassen NA 1974 Control of cerebral circulation in health and disease. Circ Res $34: 749-760$

20. Greisen S, Skov L 1991 Changing inspired oxygen fraction may alter cerebra haemoglobin concentration as detected by near infrared spectroscopy. 4th International Conference on Fetal and Neonatal Physiological Measurements. Elsevier (in press)

\section{APPENDIX}

Analyzing program. The $\mathrm{SaO}_{2}$ signal and the NIRS signals were sampled at $2 \mathrm{~Hz}$. Cerebral oxyhemoglobin $\left(\mathrm{HbO}_{2}\right)$, deoxyhemoglobin $(\mathrm{HB})$, and total $\mathrm{Hb}$ concentrations $(\mathrm{tHb})$ were calculated as previously described (5).

Cerebral oxygenation index $(\mathrm{OI})$ was calculated as $\left(\mathrm{HbO}_{2}-\right.$ $\mathrm{HB}) / 2$.

The CBFnirs algorithm consisted of the following steps:

A. Smoothing of $\mathrm{SaO}_{2}$ and OI using five points $(2.5 \mathrm{~s}$ of data):

$$
\begin{aligned}
\mathrm{S}(\mathrm{t})= & 0.1 \cdot \mathrm{R}(\mathrm{t}-2)+0.2 \cdot \mathrm{R}(\mathrm{t}-1)+0.4 \cdot \mathrm{R}(\mathrm{t}) \\
& +0.2 \cdot \mathrm{R}(\mathrm{t}+1)+0.1 \cdot \mathrm{R}(\mathrm{t}+2)
\end{aligned}
$$

where $S(t)$ is a point of smoothed data and $R(t-2)$ to $R(t+2)$ are five points of raw data.

B. 1. Detection of the time of the abrupt $\mathrm{SaO}_{2}$ increase, $t_{s}$; and

2. Detection of the time of the abrupt OI increase, $t_{0}$.

C. Quality tests:

1. $\mathrm{SaO}_{2}$ increasing more than $2 \%$ in the $10 \mathrm{~s}$ after $\mathrm{t}_{\mathrm{s}}$;

2. The mean of $\mathrm{SaO}_{2}$ differing less than $1 \%$ between the periods from $30-40 \mathrm{~s}$ and $10-0 \mathrm{~s}$ before $t_{s}$;

3. The variation in $\mathrm{OI}$ in the $40 \mathrm{~s}$ period preceding $t_{\mathrm{o}}$ being less than 0.3 times the change in $\mathrm{OI}$ in the $10 \mathrm{~s}$ after $\mathrm{t}_{\mathrm{o}}$;

4. The change in $\mathrm{tHb}$ in the $10 \mathrm{~s}$ after $\mathrm{t}_{\mathrm{o}}$ being less than 0.3 times the change in $\mathrm{OI}$ in the same period; and

5. The delay of $t_{0}$ relative to $t_{s}$ being within the range of -4 to $4 \mathrm{~s}$

If passing quality tests:

D. Fitting a 4th order polynomial to OI from $t_{0}$ to $t_{0}+10 s$;

E. Calculating the baseline for $\mathrm{SaO}_{2}$ for the period $t_{s-5 s}$ to $t_{s}$, $\mathrm{SaO}_{2}$ base and

F. Calculating CBFnirs(i) for $\mathrm{i}=6$ and $7.5 \mathrm{~s}$.

$\mathrm{CBF}=\mathrm{k} \times\left[\mathrm{OI}\left(\mathrm{t}_{\mathrm{o}+\mathrm{i}}\right)-\mathrm{OI}\left(\mathrm{t}_{\mathrm{o}}\right)\right] / \sum_{\mathrm{t}_{\mathrm{s}}}^{\mathrm{t}_{\mathrm{s}}+\mathrm{i}}\left(\mathrm{SaO}_{2}(\mathrm{t})-\mathrm{SaO}_{2}\right.$ base $)$

G. Reestimate CBFnirs(i):

1. For ts $=$ ts +2 and to $=$ to +2 ; and

2. For $\mathrm{j}=\mathrm{i} \pm 1$ to evaluate conformity to model and stability of estimate. 